\title{
LETTERS
}

\section{Recent alveolar echinococcosis cases in North America warrant further investigation}

Overall, Dr. Christopher Olivier and colleagues' article on disseminated alveolar echinococcosis ${ }^{1}$ is interesting and important, but some clarifications are needed:

1. Alveolar echinococcosis (the disease) is not yet endemic in Canada; its etiological agent, Echinococcus multilocularis, is. ${ }^{2,3}$

2. In the absence of a clear travel history excluding allochthonous infection, typing the parasite strain responsible for human infections is pivotal to understanding the origin of infection. Most recent alveolar echinococcosis cases in North America were caused by infections acquired elsewhere (mostly in Europe or Asia) until 2013, ${ }^{2}$ when an outbreak of locally acquired cases caused by a newly endemic strain of probable European origin was detected in Alberta. ${ }^{4}$

3. Echinococcus multilocularis infections in wildlife in Ontario are increasing but they are not at a high prevalence level. ${ }^{5}$

4. I am not certain whether humans should be defined as aberrant hosts; they would probably be better described as accidental or dead-end hosts. An example of aberrant hosts would be dogs that develop canine alveolar echinococcosis whereas, as definitive hosts, they should be immune to infections from eggs, which they naturally shed.

\section{Alessandro Massolo PhD}

Associate professor of behavioural ecology, Department of Biology, University of Pisa, Pisa, Italy; adjunct professor of wildlife health ecology, Department of Ecosystems and Public Health, Faculty of Veterinary Medicine, University of Calgary, Calgary, Alta.

Cite as: CMAJ 2019 December 2;191: E1338. doi: $10.1503 / \mathrm{cmaj} .73510$

\section{References}

1. Olivier CJ, Li H, Auer RN, et al. Disseminated alveolar echinococcosis in a 74-year-old woman presenting with focal seizure. CMAJ 2019;191:E940-3.

2. Massolo A, Liccioli S, Budke C, et al. Echinococcus multilocularis in North America: the great unknown. Parasite 2014;21:23.

3. Deplazes P, Rinaldi L, Alvarez Rojas CA, et al. Global distribution of alveolar and cystic echinococcosis. Adv Parasitol 2017;95:315-493.

4. Massolo A, Klein C, Kowalewska-Grochowska K, et al. European Echinococcus multilocularis identified in patients in Canada. N Engl J Med 2019; 381:384-5.

5. Kotwa JD, Isaksson M, Jardine CM, et al. Echinococcus multilocularis infection, Southern Ontario, Canada. Emerg Infect Dis;25:265-72.

Competing interests: None declared 